\title{
PENYELESAIAN SISTEM PERSAMAAN LINIER FULLY FUZZY MENGGUNAKAN METODE DEKOMPOSISI NILAI SINGULAR (SVD)
}

\section{Corry Corazon Marzuki ${ }^{1}$, Agustian $^{2}$, Dewi Hariati ${ }^{3}, J^{\prime}$ initis Afmilda ${ }^{4}$, Nurul Husna $^{5}$, Putra Nanda ${ }^{6}$}

Jurusan Matematika, Fakultas Sains dan Teknologi, UIN Sultan Syarif Kasim Riau 1,2,3,4,5,6, Jl. HR. Soebrantas No. 155 Simpang Baru, Panam, Pekanbaru, 28293

Email: corry@uin-suska.ac.id ${ }^{1}$, agustian2196@gmail.com², dewih961002@gmail.com³, junitisafmilda21@gmail.com ${ }^{4}$, husnanuru12411@gmail.com ${ }^{5}$, putrananda581@gmail.com 6

DOI:https://doi.org/10.15642/mantik.2018.4.1.143-149

\begin{abstract}
Abstrak
Sistem persamaan linear dapat dibentuk ke dalam persamaan matriks $\mathrm{AX}=\mathrm{B}$. Konstanta dalam persamaan linear dapat pula berupa bilangan fuzzy dan semua parameternya dalam bilangan fuzzy yang dikenal dengan istilah sistem persamaan linear fully fuzzy. Metode Singular Value Decomposition (SVD) merupakan suatu metode yang mendekomposisikan suatu matriks A menjadi tiga komponen matriks USV ${ }^{\mathrm{H}}$. Metode SVD dapat digunakan untuk mencari solusi dari sistem persamaan linear fully fuzzy yang konsisten maupun sistem persamaan linear fully fuzzy yang tidak konsisten. Solusi yang diperoleh dari sistem persamaan linear fully fuzzy yang konsisten dengan menggunakan SVD adalah solusi tunggal dan banyak solusi. Sedangkan, solusi yang diperoleh dari sistem persamaan linear fully fuzzy yang tidak konsisten dengan menggunakan SVD adalah solusi pendekatan terbaik.
\end{abstract}

Kata kunci: fuzzy, sistem persamaan linier fully fuzzy, singular value decomposition (SVD)

\begin{abstract}
Linear equation system can be arranged into the $\mathrm{AX}=\mathrm{B}$ matrix equation. Constants in linear can also contain fuzzy numbers and all their parameters in fuzzy numbers known as fully fuzzy linear equation systems. singular value decomposition (SVD) is a method that decomposes an A matrix into three components of the USV ${ }^{\mathrm{H}}$. The SVD method can be used to find a solution to the fully fuzzy fully linear equation system that is also an inconsistent fully fuzzy linear equation system. The solution obtained from a fully fuzzy linear equation system that is consistent using SVD is a single solution and many solutions. Whereas, the solution obtained from a fully fuzzy linear equation system that is inconsistent using SVD is the best approach solution.
\end{abstract}

Keywords: fuzzy, fully fuzzy linear equation system, singular value decomposition (SVD)

\section{Pendahuluan}

Sistem persamaan linier merupakan kumpulan persamaan linier yang saling berhubungan untuk mencari nilai variabel yang memenuhi semua persamaan linier tersebut. Sistem persamaan linier biasanya terdiri atas $m$ persamaan dan $n$ variabel. Sistem persamaan linier dapat ditulis dalam bentuk persamaan matriks $A X=B$, dengan semua entri-entri di dalam $A$ dan $B$ adalah bilangan riil. Seiring perkembangan ilmu matematika, konstanta dalam sistem persamaan linier dapat berupa bilangan fuzzy dan dapat diselesaikan dengan menggunakan metode yang sama. Sistem persamaan linier dengan konstanta berupa bilangan fuzzy disebut sistem persamaan linier fuzzy. Bentuk persamaan linier fuzzy 
seperti sistem persamaan linier biasa, perbedaannya terletak pada unsur $B$. Unsur $B$ dalam sistem persamaan linier fuzzy merupakan bentuk parameter yang berada pada interval tertentu. Selain itu, dikenal juga sistem persamaan linier fully fuzzy. Sistem persamaan fully fuzzy merupakan persamaan matriks $A X=B$ dengan $A$ adalah matriks fuzzy dan $X, B$ adalah bilangan fuzzy. Gourav Gupta melakukan penelitian pada Tahun 2010 tentang penyelesaian sistem persamaan linier fully fuzzy menggunakan metode langsung (metode invers matriks, aturan Cramer, dan metode dekomposisi LU) dan metode iterasi (metode Gauss Jacobi dan Gauss Seidel) dengan judul penelitian "Some Methods for Solving Fully Fuzzy Linear System of Equations".

Beberapa metode yang dapat digunakan untuk menyelesaikan sistem persamaan linear salah satunya adalalah menggunakan analisis SVD. Analisis SVD merupakan suatu teknik yang melibatkan pemfaktoran $A$ ke dalam hasil kali $U S V^{T}$, dengan $U, S, V$ adalah matriks bujur sangkar dan semua entri diluar diagonal dari matriks $S$ adalah nol. Sedangkan vektor kolom dari matriks $U$ dan $V$ adalah ortonormal. Kelebihan metode analisis SVD dalam menyelesaikan sistem persamaan linear yaitu, solusi dari sistem persamaan linear tetap dapat dicari meskipun sistem persamaan linear tersebut tidak mempunyai pemecahan, dalam hal ini solusi yang diperoleh adalah solusi pendekatan terbaik [1].

\section{Tinjauan Pustaka}

\subsection{Back-propagation Neural Network}

Sistem persamaan linier adalah sekumpulan persamaan linier yang terdiri dari persamaan $L_{1}, L_{2}, \ldots, L_{m}$, dengan $n$ variabel yang tidak diketahui yaitu $x_{1}, x_{2}$, $\ldots, x_{n}$ yang dapat dinyatakan dalam bentuk:

$$
\begin{aligned}
& a_{11} x_{1}+a_{12} x_{2}+\cdots+a_{1 n} x_{n}=b_{1} \\
& a_{21} x_{1}+a_{22} x_{2}+\cdots+a_{2 n} x_{n}=b_{2} \\
& a_{m 1} x_{1}+a_{m 2} x_{2}+\cdots+a_{m n} x_{n}=b_{m}
\end{aligned}
$$
dengan $a_{11}, a_{12}, \ldots, a_{m n}$ dan $b_{1}, b_{2}, \ldots, b_{m}$ adalah konstanta-konstanta bilangan riil.
Menyelesaikan suatu sistem persamaan linier adalah mencari nilai variabel-variabel yang memenuhi sistem persamaan linier tersebut. Sistem persamaan linier dikatakan konsisten jika memiliki satu atau banyak solusi sedangkan tidak konsisten jika tidak mempunyai solusi penyelesaian.

Sistem persamaan linier dapat dinyatakan dalam bentuk matriks seperti berikut [2].

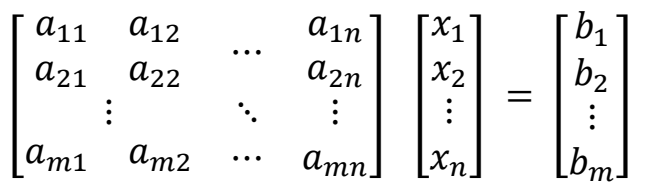

atau $A x=b$

$$
\operatorname{dan} b=\left[\begin{array}{c}
b_{1} \\
b_{2} \\
\vdots \\
b_{m}
\end{array}\right]
$$

$$
\text { dengan } \quad A=\left[\begin{array}{cccc}
a_{11} & a_{12} & & a_{1 n} \\
a_{21} & a_{22} & \cdots & a_{2 n} \\
& \vdots & \ddots & \vdots \\
a_{m 1} & a_{m 2} & \cdots & a_{m n}
\end{array}\right]
$$

\subsection{Resilent Back-propagation (Rprop)}

Fuzzy dapat diartikan kabur atau semu. Himpunan fuzzy pertama kali dibahas oleh Lotfi A. Zadeh 1965 Himpunan fuzzy merupakan kumpulan dari entri-entri dengan satu rangkaian tingkat keanggotaan. Secara fungsional himpunan fuzzy disajikan dalam bentuk persamaan matematis sehingga untuk mengetahui derajat keanggotaan dari masing-masing elemen memerlukan perhitungan.

Definisi 2: Misalkan $X$ adalah suatu himpunan semesta, kemudian himpunan bagian fuzzy $U$ dari $X$ adalah himpunan bagian dari $X$ yang keanggotaannya didefinisikan melalui fungsi keanggotaan sebagai berikut:

$$
\mu_{\widetilde{u}}: X \rightarrow[0,1]
$$

Berdasarkan definisi tersebut maka himpunan fuzzy $\widetilde{U}$ dalam himpunan semesta $x$, ditulis dalam bentuk:

$$
\widetilde{U}=\left\{\left(x, \mu_{\widetilde{u}} x\right) \mid x \in X\right\}
$$

dengan $\left(x, \mu_{\widetilde{u}} x\right)$, menyatakan elemen $x$ yang mempunyai derajat keanggotaan $\mu_{\tilde{u}} x$ 
Himpunan bilangan fuzzy dinamakan bilangan fuzzy segitiga jika fungsi keanggotaannya sebagai berikut [2]:

$\mu_{\widetilde{u}} x$
$=\left\{\begin{array}{c}1-\frac{m-x}{\alpha} \text { untuk } m-a<x \leq m \text { dan } a>0 \\ 1-\frac{x-m}{\beta} \text { untuk } m \leq x<m+\beta \text { dan } \beta>0 \\ 0 \text { untuk } x \leq m-\text { a atau } x \geq m+\beta\end{array}\right.$

\subsection{Fungsi Aktivasi}

Sistem Persamaan Linear fully fuzzy dapat ditulis menjadi bentuk perkalian matriks fuzzy. Sistem persamaan linier fully fuzzy merupakan sebuah sistem persamaan linier yang semua parameternya dalam bentuk fuzzy [4].

Definisi 3: Matriks $\tilde{A}=\left(\tilde{a}_{i j}\right)$ disebut dengan matriks fuzzy, jika setiap elemen $\tilde{A}$ adalah bilangan fuzzy. Sebuah matriks fuzzy $\tilde{A}$ bernilai positif yang dinotasikan dengan $\tilde{A}>0$, jika setiap elemen positif. Kita dapat mengatakan matriks fuzzy $n \times$ $n \tilde{A}=\left(\tilde{a}_{i j}\right)_{n \times n}, \quad$ yang mana $\tilde{a}_{i j}=$ $\left(a_{i j}, \alpha_{i j}, \beta_{i j}\right)$, dengan notasi baru $\tilde{A}=$ $(A, M, N)$ dimana $A=\left(a_{i j}\right)_{n \times n} \cdot M=$ $\left(m_{i j}\right)_{n \times n}$ dan $\quad N=\left(n_{i j}\right)_{n \times n}$ adalah matriks tegas.

Definisi 4 Dua bilangan fuzzy dengan matriks $\tilde{A}=\left(a_{1}, a_{2}, a_{3}\right)$ dan $\tilde{B}=$ $\left(b_{1}, b_{2}, b_{3}\right)$ dikatakan sama, jika dan hanya jika $a_{1}=b_{1}, a_{2}=b_{2}$ dan $a_{3}=b_{3}$.

Definisi 5 (Jika $\tilde{A}=\left(a_{1}, a_{2}, a_{3}\right)>0$, $\tilde{B}=\left(b_{1}, b_{2}, b_{3}\right)>0, \quad$ maka: $\quad \tilde{A} \otimes \tilde{B}=$ $\left(a_{1}, a_{2}, a_{3}\right) \otimes\left(b_{1}, b_{2}, b_{3}\right) \cong$ $\left(a_{1} b_{1}, b_{1} a_{2}+a_{1} b_{2}, b_{1} a_{3}+a_{3} b_{1}\right)$.

Definisi 6 Misalkan sistem persamaan linear fuzzy $n \times n$ sebagai berikut: $\left(\tilde{a}_{11} \otimes \tilde{x}_{1}\right) \oplus\left(\tilde{a}_{12} \otimes \tilde{x}_{2}\right) \oplus \ldots$

$$
\begin{aligned}
& \oplus\left(\tilde{a}_{1 n} \otimes \tilde{x}_{n}\right)=\tilde{b}_{1} \\
& \left(\tilde{a}_{21} \otimes \tilde{x}_{1}\right) \oplus\left(\tilde{a}_{22} \otimes \tilde{x}_{2}\right) \oplus \ldots \\
& \oplus\left(\tilde{a}_{2 n} \otimes \tilde{x}_{n}\right)=\tilde{b}_{2} \\
& \left(\tilde{a}_{n 1} \otimes \tilde{x}_{1}\right) \oplus\left(\tilde{a}_{n 2} \otimes \tilde{x}_{2}\right) \oplus \ldots \\
& \oplus\left(\tilde{a}_{n n} \otimes \tilde{x}_{n}\right)=\tilde{b}_{n}
\end{aligned}
$$

Bentuk matriks dari persamaan diatas adalah:

$$
\tilde{A} \otimes \tilde{x}=\tilde{b}
$$

dari bentuk diatas dapat diartikan bahwa matriks koefisien semua parameternya dalam bentuk bilangan fuzzy [5].

Dimana matriks koefisien $\tilde{A}=\left(\tilde{a}_{i j}\right)$ $, 1 \leq i, j \leq n$ adalah matriks fuzzy $n \times n$ dan $\tilde{x}_{j}, \tilde{b}_{j} \in F(R)$, dimana $F(R)$ adalah himpunan bilangan fuzzy segitiga. Sistem ini disebut sistem linear fully fuzzy. Solusi sistem persamaan linear fully fuzzy $\tilde{A} \otimes$ $\tilde{x}=\tilde{b}$, diperoleh dari tiga sistem persamaan linear berikut:

$$
\begin{aligned}
& A x=b \\
& A y+M x=g \\
& A z+N x=h
\end{aligned}
$$

Diasumsikan bahwa adalah sebuah matriks nonsingular maka diperoleh solusi sebagai berikut:

$$
\begin{array}{ll}
A x=b & \Rightarrow x=A^{-1} b \\
A y+M x=g & \Rightarrow \mathrm{y} \\
& =A^{-1}(g-M x) \\
A z+N x=h & \Rightarrow z=A^{-1}(h-N x)
\end{array}
$$

\subsection{MAPE}

Misalkan $V$ adalah ruang hasil kali dalam. Vektor-vektor $u, v \in V$ dan $u$ dikatakan ortogonal terhadap $v$ jika $\langle u, v\rangle=0$. Berikut akan diberikan definisi tentang ortogonal.

Definisi 7: Vektor $u, v \in R^{n}$ dikatakan ortogonal jika dan hanya jika $\langle u, v\rangle=0$.

Berikut akan diberikan teorema basis ortonormal.

Teorema 8 Jika $S=v_{1}, v_{2}, \ldots, v_{n}$ adalah basis ortonormal untuk ruang hasil kali dalam $V$, dan $u$ adalah sebarang vektor dalam $V$, maka [1]

$$
\begin{aligned}
u=\left\langle u, v_{1}\right\rangle v_{1} & +\left\langle u, v_{2}\right\rangle v_{2}+\cdots \\
& +\left\langle u, v_{n}\right\rangle v_{n}
\end{aligned}
$$

\subsection{Nilai Eigen dan Vektor Eigen}

Untuk mencari nilai eigen matriks $A$ yang berukuran $n \times n$ maka kita menuliskannya sebagai berikut:

$A x=\lambda x$ atau $A x-\lambda \mathrm{I} x=0$

dan persamaan di atas akan mempunyai penyelesaian jika

$|A-\lambda \mathrm{I}|=0$

Persamaan di atas disebut sebagai persamaan karakteristik $A$. Mencari nilai eigen berarti menghitung determinan tersebut sehingga diperoleh nilai-nilai $\lambda$. 
Berikut akan diberikan definisi tentang nilai eigen dan vektor eigen.

Definisi 9: Jika $A$ adalah matriks $n \times n$, maka vektor tak nol $x$ di dalam $R^{n}$ dinamakan vektor eigen dari $A$ jika $A x$ adalah kelipatan skalar dari $x$, yaitu: $A x=$ $\lambda x$, untuk suatu skalar $\lambda$. Skalar $\lambda$ disebut nilai eigen dari $A$ dan $x$ dikatakan vektor eigen yang bersesuaian dengan $\lambda[6]$.

\subsection{Metode Singular Value Decomposition (SVD)}

Singular Value Decomposition (SVD) adalah suatu metode yang mendekomposisikan matriks $A$ menjadi tiga komponen yaitu $U S V^{T}$, yang mana salah satu dari matriks tersebut entrinya merupakan nilai singular dari matriks $A$ [7].

Berikut ini akan diberikan penjelasan tentang matriks $U, S$, dan $V$ :

Matriks $S$ adalah Matriks $S$ disebut matriks nilai singular dari $A$ karena entri diagonal dari matriks $S$ diisi dengan nilai singular dari $A$ sedangkan entri selain diagonalnya adalah nol. Matriks $S$ berukuran $m x n$ dan mempunyai bentuk: $b=\operatorname{proy}_{R(A)} b \quad$ sehingga menurut Persamaan (3) diperoleh persamaan:

$$
b=\sum_{k=1}^{r}\left\langle b, u_{k}\right\rangle u_{k}
$$

Karena $u_{k}=\frac{1}{\sigma_{k}} A v_{k}$, maka

$$
b=\sum_{k=1}^{r}\left\langle b, u_{k}\right\rangle \frac{A v_{k}}{\sigma_{k}}
$$

Operasi matriks bersifat linier, maka persamaan diatas dapat ditulis menjadi:

$b=A \sum_{k=1}^{r}\left\langle b, u_{k}\right\rangle \frac{v_{k}}{\sigma_{k}}$

Dengan membandingkan Persamaan dengan Persamaan (2), didapatkan

$x=\sum_{k=1}^{r} \frac{\left\langle b, u_{k}\right\rangle}{\sigma_{k}} v_{k}$

yang merupakan solusi dari SPL fully fuzzy pada Persamaan (1). Tetapi, nilai solusi dari sistem linier bergantung pada ruang nol dari matriks $A$ yaitu $N(A)$. Sehingga ada dua subkasus, yaitu:
a. Jika $N(A)=\{0\}$, maka sistem persamaan linear fully fuzzy mempunyai satu solusi atau solusi tunggal, yang mana solusinya diberikan oleh Persamaan (5).

b. Jika $N(A) \neq\{0\}$, maka sistem persamaan linear fully fuzzy mempunyai banyak solusi. Solusinya diberikan oleh:

$$
\begin{aligned}
& x_{\text {inf }}=\sum_{k=1}^{r} \frac{\left\langle b, u_{k}\right\rangle}{\sigma_{k}} v_{k}+ \\
& \sum_{k=r+1}^{n} \mu_{k} v_{k}(6) \\
& \text { yang diperoleh dari: }
\end{aligned}
$$

Setiap solusi umum dari SPL dapat dinyatakan dengan $X=x+x_{n}$, dimana $x_{n} \in N(A)$. Pada subkasus a, $N(A)=\{0\}$ sehingga $X=x$. Namun karena pada kasus $N(A) \neq\{0\}$, maka terdapat titik $x_{n} \in N(A)$ sedikimikian sehingga $A x_{N}=0$. Jadi, solusi umum untuk kasus ini adalah $X=x+x_{N}$, atau disini dinotasikan dengan

$x_{\text {inf }}=x+x_{n} \quad(7)$

Dengan demikian, untuk setiap titiktitiknya berlaku

$A\left(x_{\text {inf }}\right)=A\left(x+x_{n}\right)=A x+$ $A x_{n}=b+0=b$.

Setiap titik-titik $x_{N}$ dapat dinyatakan sebagai kombinasi linier dari vektor basis. Karena $\left\{v_{r+1}, v_{r+2}, \ldots, v_{n}\right\}$ merupakan basis untuk $N(A)$, maka $x_{N}$ dapat dinyatakan dengan

$x_{n}=\sum_{k=r+1}^{n} \mu_{k} v_{k}$

Sebelumnya telah diketahui dari Persamaan (5), sehingga $x_{\text {inf }}=x+$ $x_{n}$ dapat dinyatakan dengan

$$
x_{\text {inf }}=\sum_{k=1}^{r} \frac{\left\langle b, u_{k}\right\rangle}{\sigma_{k}} v_{k}+\sum_{k=r+1}^{n} \mu_{k} v_{k}
$$

Kasus untuk $b \notin R(A)$

Pada kasus ini sistem tidak mempunyai solusi, sehingga hanya bisa dihitung pendekatan terbaik dari solusinya. Dalam hal ini, solusi pendekatan terbaik tersebut adalah vektor $x_{r}$ sehingga

$A x_{r}=b_{r}$

dimana $b_{r}$ dalam $R(A)$, dan $b_{r}$ adalah vektor yang terdekat dengan $b$. Solusi pendekatan terbaik pada kasus ini diberikan juga oleh Persamaan (4), yaitu:

$x_{r}=\sum_{k=1}^{r} \frac{\left\langle b, u_{k}\right\rangle}{\sigma_{k}} v_{k}$ 
$x_{r}$ disebut sebagai solusi pendekatan terbaik, artinya jika $A x_{r}=b_{r}$, maka $b_{r}$ adalah vektor di $R(A)$ yang terdekat dengan $b$. Sehingga vektor $\left(b-b_{r}\right)$ akan tegak lurus dengan setiap vektor di $R(A)$ termasuk vektor yang merentang $R(A)$ yaitu vektor -vektor $u_{i}$ dengan $1 \leq i \leq r$, $u_{i}$ adalah vektor yang ortonormal, maka berlaku:

$$
\begin{gathered}
\left\langle\left(b-b_{r}\right), u_{i}\right\rangle=\left\langle\left(b-A x_{r}\right), u_{i}\right\rangle \\
=\left\langle\left(b-A\left(\sum_{k=1}^{r} \frac{\left\langle b, u_{k}\right\rangle}{\sigma_{k}} v_{k}\right)\right), u_{i}\right\rangle \\
=\left\langle b, u_{i}\right\rangle-\left\langle b, u_{i}\right\rangle=0
\end{gathered}
$$

Hal ini menunjukkan bahwa $(b-$ $\left.A x_{r}\right)$ adalah tegak lurus dengan setiap vektor di $R(A)$ dan Persamaan (10) merupakan solusi pendekatan terbaik [8].

Contoh 1

Diberikan sistem persamaan linear fully fuzzy sebagai berikut:

$(19,1,1) \otimes\left(x_{1}, y_{1}, z_{1}\right) \oplus(12,1.5,1.5)$

$\otimes\left(x_{2}, y_{2}, z_{2}\right) \oplus(6,0.5,0.2) \otimes\left(x_{3}, y_{3}, z_{3}\right)$

$=(1897,427.7,536.2)$

$(2,0.1,0.1) \otimes\left(x_{1}, y_{1}, z_{1}\right) \oplus(4,0.1,0.4)$

$\otimes\left(x_{2}, y_{2}, z_{2}\right) \oplus(15,0.2,0.2) \otimes\left(x_{3}, y_{3}, z_{3}\right)$

$=(434.5,76.2,109.3)$

$(2,0.1,0.2) \otimes\left(x_{1}, y_{1}, z_{1}\right) \oplus(2,0.1,0.3)$

$\otimes\left(x_{2}, y_{2}, z_{2}\right) \oplus(4.5,0.1,0.1) \otimes\left(x_{3}, y_{3}, z_{3}\right)$

$=(535.5,88.3,131.9)$

Carilah solusi dari SPL fully fuzzy diatas.

Penyelesaian:

1. Mengubah bentuk persamaan ke dalam matriks $\quad \tilde{A} \otimes \tilde{x}=\tilde{b}$ dimana $\quad \tilde{A}=$ $(A, M, N)$ dan $\tilde{b}=(b, g, h)$, dengan:

$$
\begin{aligned}
& A=\left[\begin{array}{ccc}
19 & 12 & 6 \\
2 & 4 & 1.5 \\
2 & 2 & 4.5
\end{array}\right] \\
& M=\left[\begin{array}{ccc}
1 & 1.5 & 0.5 \\
0.1 & 0.1 & 0.2 \\
0.1 & 0.1 & 0.1
\end{array}\right] \\
& N=\left[\begin{array}{ccc}
1 & 1.5 & 0.2 \\
0.1 & 0.4 & 0.2 \\
0.2 & 0.3 & 0.1
\end{array}\right]
\end{aligned}
$$

$$
\begin{aligned}
& b=\left[\begin{array}{l}
1897 \\
434.5 \\
535.5
\end{array}\right] \\
& h=\left[\begin{array}{l}
536.2 \\
109.3 \\
131.9
\end{array}\right]
\end{aligned}
$$$$
g=\left[\begin{array}{l}
427.7 \\
76.2 \\
88.3
\end{array}\right]
$$

Selanjutnya ubah matriks tersebut ke dalam bentuk sistem persamaan linear pada Persamaan (1) sebagai berikut: $A x=b$

$$
\begin{aligned}
& {\left[\begin{array}{ccc}
19 & 12 & 6 \\
2 & 4 & 1.5 \\
2 & 2 & 4.5
\end{array}\right]\left[\begin{array}{l}
x_{1} \\
x_{2} \\
x_{3}
\end{array}\right]=\left[\begin{array}{l}
1897 \\
434.5 \\
535.5
\end{array}\right]} \\
& A y+M x=g
\end{aligned}
$$

$$
\begin{aligned}
& {\left[\begin{array}{ccc}
19 & 12 & 6 \\
2 & 4 & 1.5 \\
2 & 2 & 4.5
\end{array}\right]\left[\begin{array}{l}
y_{1} \\
y_{2} \\
y_{3}
\end{array}\right]+} \\
& {\left[\begin{array}{ccc}
1 & 1.5 & 0.5 \\
0.1 & 0.1 & 0.2 \\
0.1 & 0.1 & 0.1
\end{array}\right]\left[\begin{array}{l}
x_{1} \\
x_{2} \\
x_{3}
\end{array}\right]=\left[\begin{array}{c}
427.7 \\
76.2 \\
88.3
\end{array}\right]}
\end{aligned}
$$

$A z+N x=h$

$$
\begin{aligned}
& {\left[\begin{array}{ccc}
19 & 12 & 6 \\
2 & 4 & 1.5 \\
2 & 2 & 4.5
\end{array}\right]\left[\begin{array}{l}
z_{1} \\
z_{2} \\
z_{3}
\end{array}\right]+} \\
& {\left[\begin{array}{ccc}
1 & 1.5 & 0.2 \\
0.1 & 0.4 & 0.2 \\
0.2 & 0.3 & 0.1
\end{array}\right]\left[\begin{array}{l}
x_{1} \\
x_{2} \\
x_{3}
\end{array}\right]=\left[\begin{array}{l}
536.2 \\
109.3 \\
131.9
\end{array}\right]} \\
& (12)
\end{aligned}
$$

Dari Persamaan (10) maka persamaan yang terbentuk adalah sebagai berikut:

$$
\begin{aligned}
& 19 x_{1}+12 x_{2}+6 x_{3}=1897 \\
& 2 x_{1}+4 x_{2}+1.5 x_{3}=434.5 \\
& 2 x_{1}+2 x_{2}+4.5 x_{3}=535.5
\end{aligned}
$$

2. Mencari nilai eigen dan vektor eigen Didapat nilai-nilai eigen dari $A^{H} A$ adalah $\lambda_{1}=4.4403, \lambda_{2}=14.0393$ dan $\lambda_{3}=573.0204$

Didapat vektor eigen untuk $\lambda_{1}=$ 4.4403, yaitu:

$x_{1}=\left[\begin{array}{lll}0.4401 & -0.8372 & 0.3229\end{array}\right]$

Didapat vektor eigen untuk $\lambda_{2}=$ 14.0393, yaitu:

$$
x_{2}=\left[\begin{array}{lll}
-0.4099 & 0.1325 & 0.9024
\end{array}\right]
$$

Didapat vektor eigen untuk $\lambda_{3}=$ 573,0204, yaitu:

$x_{3}=\left[\begin{array}{lll}0.7960 & 0.5295 & 0.2852\end{array}\right]$ 
3. Mendekomposisikan matriks $A$ menjadi tiga komponen matriks $U S V^{H}$

a. Menyusun matriks $S$

Nilai singular dari matriks $A$, yaitu:

$$
\begin{gathered}
\sigma_{1}=\sqrt{\lambda_{1}}=\sqrt{4.4403}=2.1072 \\
\sigma_{2}=\sqrt{\lambda_{2}}=\sqrt{14.0393}=3.7469 \\
\sigma_{3}=\sqrt{\lambda_{3}}=\sqrt{573.0204} \\
=23.9378
\end{gathered}
$$

matriks $\Sigma$ yang terbentuk adalah:

$$
\Sigma=\left[\begin{array}{ccc}
2.1072 & 0 & 0 \\
0 & 3.7469 & 0 \\
0 & 0 & 23.9378
\end{array}\right]
$$

Maka didapat matriks singular $S$, yaitu:

$$
S=\left[\begin{array}{ccc}
2.1072 & 0 & 0 \\
0 & 3.7469 & 0 \\
0 & 0 & 23.9378
\end{array}\right]
$$

b. Menyusun matriks $V$ dengan persamaan $v_{i}=\frac{1}{\left\|x_{i}\right\|} x_{i}$

$V=\left[\begin{array}{ccc}0.4389 & -0.4099 & 0.7977 \\ -0.8349 & 0.1325 & 0.5307 \\ 0.3220 & 0.9024 & 0.2859\end{array}\right]$

c. Menyusun matriks $U$ dengan persamaan $u_{i}=\frac{1}{\sigma_{1}} A v_{i}$

$$
=\left[\begin{array}{ccc}
0.1197 & -0.2092 & 0.9710 \\
-0.9391 & 0.2839 & 0.1732 \\
0.3118 & 0.9357 & 0.1647
\end{array}\right]
$$

Sehingga bentuk SVD dari matriks $A$ adalah:

$$
\begin{aligned}
& A=U S V^{H} \\
& A=\left[\begin{array}{ccc}
17.8112 & 12.0209 & 6.0192 \\
1.7936 & 3.9921 & 1.5074 \\
1.7991 & 2.0083 & 4.5025
\end{array}\right]
\end{aligned}
$$

4. Menentukan basis-basis ortonormal untuk $R(A), R\left(A^{H}\right), N(A)$ dan $N\left(A^{H}\right)$

a. Untuk basis $R(A)$ adalah $\left\{u_{1}, u_{2}\right\}=$ $\left\{\left[\begin{array}{c}0.1197 \\ -0.9391 \\ 0.3118\end{array}\right],\left[\begin{array}{c}-0.2092 \\ 0.2839 \\ 0.9357\end{array}\right]\right\}$

b. Untuk basis $R\left(A^{H}\right)$ adalah $\left\{v_{1}, v_{2}\right\}=$ $\left\{\left[\begin{array}{c}0.4389 \\ -0.8349 \\ 0.3220\end{array}\right],\left[\begin{array}{c}-0.4099 \\ 0.1325 \\ 0.9024\end{array}\right]\right\}$

c. Untuk basis $N(A)$ adalah $\left\{v_{3}\right\}=$ $\left\{\left[\begin{array}{l}0.7977 \\ 0.5307 \\ 0.2859\end{array}\right]\right\}$ d. Untuk basis $N\left(A^{H}\right)$ adalah $\left\{u_{3}\right\}=$ $\left\{\left[\begin{array}{l}0.9710 \\ 0.1732 \\ 0.1647\end{array}\right]\right\}$

5. Menentukan apakah $b$ sama dengan proyeksi $b$ pada $R(A)$

$$
\begin{gathered}
\operatorname{proy}_{R(A)} b=\sum_{k=1}^{3}\left\langle b, u_{k}\right\rangle u_{k} \\
=\left\langle b, u_{1}\right\rangle u_{1}+\left\langle b, u_{2}\right\rangle u_{2}+\left\langle b, u_{3}\right\rangle u_{3} \\
=\left[\begin{array}{r}
-1.6757 \\
13.1466 \\
-4.3650
\end{array}\right]+\left[\begin{array}{c}
-47.6075 \\
64.6070 \\
212.9368
\end{array}\right] \\
+\left[\begin{array}{c}
1947.2434 \\
347.3353 \\
330.2894
\end{array}\right] \\
=\left[\begin{array}{c}
1897,9602 \\
425,0889 \\
538,8612
\end{array}\right]
\end{gathered}
$$

Berdasarkan perhitungan tersebut

$$
\text { diperoleh } \operatorname{proy}_{R(A)} b \neq b=\left[\begin{array}{l}
1897 \\
434.5 \\
535,5
\end{array}\right] \text {. }
$$

Karena $\operatorname{proy}_{R(A)} b \neq b$, berarti $b \notin$ $R(A)$. Hal tersebut menandakan SPL ini tidak mempunyai solusi. Akan tetapi solusi pendekatan terbaiknya dapat dicari, yaitu:

$$
\begin{gathered}
x_{r}=\sum_{k=1}^{3} \frac{\left\langle b, u_{k}\right\rangle}{\sigma_{k}} v_{k} \\
=\frac{\left\langle b, u_{1}\right\rangle}{\sigma_{1}} v_{1}+\frac{\left\langle b, u_{2}\right\rangle}{\sigma_{2}} v_{2}+\frac{\left\langle b, u_{3}\right\rangle}{\sigma_{3}} v_{3} \\
=\left[\begin{array}{c}
-2.9158 \\
5.5466 \\
-2.1392
\end{array}\right]+\left[\begin{array}{c}
-24.8954 \\
8.0475 \\
54.8076
\end{array}\right] \\
+\left[\begin{array}{l}
66.8277 \\
44.4596 \\
23.9514
\end{array}\right] \\
=\left[\begin{array}{c}
39.0165 \\
58.0537 \\
76.6198
\end{array}\right]
\end{gathered}
$$

Jadi solusi pendekatan terbaik dari SPL ini adalah: $x_{1}=39.0165, \quad x_{2}=58.0537$ dan $x_{3}=76.6198$. Dengan cara yang sama kita dapat memperoleh solusi terbaik untuk nilai $y_{1}=7.5421, y_{2}=8.8263$ dan $y_{3}=10.3688$ serta nilai $z_{1}=13,7228, z_{2}=4,0627$, dan $z_{3}=14,2515$.

\section{Referensi}


[1] Haidir Ahmad, Irdam dan Lucia Ratnasari. "Menyelesaikan Sistem Persamaan Linear Menggunakan Analisis SVD". Jurnal Matematika Vol. 13, No.1;40-45. 2010.

[2] Rosalina. F, Farida. Y, and Hamid. A. "Metode Logika Fuzzy Sebagai Evaluasi Distribusi Daya Listrik Berdasarkan Beban Puncak Pembangkit Tenaga Listrik", mantik, Vol. 2, No. 1, : 22-29.2016.

[3] Howard, Anton. "Elementary Linear Algebra", Eighth Edition. John Wiley, New York. 2000.

[4] Kholifah. Penyelesaian Sistem Persamaan Linear Fully Fuzzy Menggunakan Metode Gauss Saidel. Pekanbaru: SKRIPSI Jurusan Matematika Universitas Islam Negeri Sultan Syarif Kasim Riau. 2013.
[5] K. Jaikumar and S. Sunantha. "SST Decomposition Methot for Solving Fully Fuzzy Linear Systems".Int. J. Industrial Mathematics. Vol. 5, No. 4. 2013.

[6] Sutojo, T. dkk. "Teori dan Aplikasi Aljabar Linear dan Matriks". Andi: Yogyakarta. 2010.

[7] Marni, Sabrina Indah. Penyelesaian Sistem Persamaan Linear Fuzzy Menggunakan Metode Dekomposisi Nilai Singular (SVD): SKRIPSI Jurusan Matematika Universitas Islam Negeri Sultan Syarif Kasim Riau. 2013.

[8] Marzuki, Corry Corazon dan Herawati. "Penyelesaian Sistem Persamaan Linear Fully Fuzzy Menggunakan Iterasi Jacobi”. Vol. 1, No.1, ISSN: 2460-4542, Januari 2015, Pekanbaru. (2015). 